Check for updates

Cite this: RSC Adv., 2017, 7, 54422

Received 12th October 2017

Accepted 17th November 2017

DOI: 10.1039/c7ra11235a

rsc.li/rsc-advances

\section{Adsorption of carbon dioxide by a novel amine impregnated ZSM-5/KIT-6 composite}

\begin{abstract}
Zhifeng Lin, (D) Jianwen Wei, (DD * Linlin Geng, Dejun Mei and Lei Liao
A novel amine modified composite was fabricated for $\mathrm{CO}_{2}$ capture. Tetraethylenepentamine (TEPA) or polyethyleneimine (PEI) was selected to modify the micro/mesoporous ZSM-5/KIT-6 composite (ZK). With the porous nature of the support, large amine loadings from 50 to $80 \%$ were expected via a typical impregnation step. The $\mathrm{CO}_{2}$ adsorption performance was investigated by thermal gravimetric analysis (TGA) in mixed gases $\left(15 \% \mathrm{CO}_{2}\right.$ and the balance is $\left.\mathrm{N}_{2}\right)$ at $30-90{ }^{\circ} \mathrm{C}$. With higher nitrogen content and better texture properties (surface area and total pore volume), TEPA-loaded materials exhibited better adsorption capacities than PEI-loaded materials. In the two series of samples, ZK-TEPA-60 and ZK-PEI60 displayed outstanding $\mathrm{CO}_{2}$ capture, with capacities as high as 5.32 and $4.59 \mathrm{mmol} \mathrm{g}$ at 60 and $75{ }^{\circ} \mathrm{C}$, respectively. ZK-TEPA-60 demonstrated relatively rapid kinetics and a higher enthalpy. The materials we designed displayed excellent $\mathrm{CO}_{2}$ adsorption performance in comparison with other amine modified solid materials, indicating the prospects of these adsorbents for $\mathrm{CO}_{2}$ capture from flue gas.
\end{abstract}

\section{Introduction}

The continuous increase in emissions of $\mathrm{CO}_{2}$ mainly derived from burning a great deal of fossil fuels is aggravating climate change and global warming. ${ }^{\mathbf{1} 2}$ The reduction of $\mathrm{CO}_{2}$ emissions is imperative for the mitigation of global warming for which capture of $\mathrm{CO}_{2}$ from flue gas is an effective method. Recently, many kinds of $\mathrm{CO}_{2}$ capture technologies have been developed to reduce $\mathrm{CO}_{2}$ emissions. ${ }^{3,4}$ Chemical absorption with amines has been commercialized on a large scale,,$^{5-7}$ but there are many adverse effects, such as wastage of solvent due to amine volatilization, demand of high energy and generation of waste during regeneration and limitation of operational lifetime due to solvent degradation. ${ }^{8-10}$ However, adsorption with porous solids has advantages, such as friendliness to the environment and long operational lifetime., ${ }^{\mathbf{5 1 1}}$ Therefore, there have been various porous materials designed as adsorbents for use in $\mathrm{CO}_{2}$ capture, such as zeolites, ${ }^{12,13}$ mesoporous silicas, ${ }^{14,15}$ metal organic frameworks, ${ }^{16-18}$ and activated carbons. ${ }^{19,20}$

Zeolites, a class of crystals with regular hole wall, such as ZSM-5, 13X, $\beta$, and 5A, have been widely used in industrial applications due to their excellent adsorption capacities at low $\mathrm{CO}_{2}$ partial pressure and high reusability in regeneration. With medium pore size and abundant microporous structure, zeolite ZSM-5 is efficient for $\mathrm{CO}_{2}$ capture through physisorption formed by van der Waals' force or hydrogen bonding. Hefti et al. found that the $\mathrm{CO}_{2}$ uptake of ZSM-5 was $1.35 \mathrm{mmol} \mathrm{g}^{-1}$ at $25{ }^{\circ} \mathrm{C}$ and $\mathrm{CO}_{2}$ partial pressure of $100 \mathrm{kPa}$ and a higher value of

Guangxi Scientific Experiment Center of Mining, Metallurgy and Environment, Guilin University of Technology, Guilin 541004, PR China. E-mail: jianwen988@126.com
$2.34 \mathrm{mmol} \mathrm{g}^{-1}$ was obtained as increasing pressure to $1000 \mathrm{kPa} .{ }^{21}$ Mesoporous silicas, a class of silica-based inorganic materials with amorphous pore wall, such as KIT-6, SBA-15, MCM-48 and MCM-41, have been widely investigated due to high pore volume and surface area. With abundant mesoporous structure and large pore size, silica-based KIT- 6 is beneficial to accommodate more amines to react with $\mathrm{CO}_{2}$ for chemisorption. As a result, KIT- 6 has demonstrated a better $\mathrm{CO}_{2}$ adsorption performance over many other silica-based materials after impregnation with polyethyleneimine (PEI) as previously reported by Son et al. ${ }^{22}$ At $75{ }^{\circ} \mathrm{C}$ and $\mathrm{CO}_{2}$ partial pressure of 101 $\mathrm{kPa}$, an maximum uptake of $3.07 \mathrm{mmol} \mathrm{g}^{-1}$ was found for PEIloaded KIT-6. ${ }^{22}$ The composites combined with zeolites and mesoporous silicas have common advantages, which are the optional adsorbents. Santos et al. fabricated micro/mesoporous composites containing zeolite ZSM-12 and mesoporous silica MCM-41 via the self-assembly procedure. ${ }^{23}$ At $25{ }^{\circ} \mathrm{C}$ and $\mathrm{CO}_{2}$ partial pressure of $101 \mathrm{kPa}$, the composite ZSM-12/MCM-41 displayed a better capacity $\left(0.94 \mathrm{mmol} \mathrm{g}^{-1}\right)$ than those of ZSM-12 (0.86 $\left.\mathrm{mmol} \mathrm{g}^{-1}\right)$ and MCM-41 $\left(0.27 \mathrm{mmol} \mathrm{g}^{-1}\right),{ }^{23}$ which is attributed to the synergistic effect. What's more, further improvement in the adsorption performance may be achieved after amine modification.

Inserting alkaline amine groups into adsorbents can improve $\mathrm{CO}_{2}$ chemisorption, which can be normally achieved in three routes: amines anchored to the supports in the form of covalent bonds, ${ }^{24,25}$ amines impregnated into the inner channel of supports ${ }^{26,27}$ and amine containing polymers introduced directly without second modification by molecular imprinting technology. ${ }^{28,29}$ In the first route, the grafted amines are usually aminosilanes. For instance, (3-aminopropyl) triethoxysilane 
(APTES) was well grafted onto the surface of KIT-6 in dry solution, presenting a uptake of $0.9 \mathrm{mmol} \mathrm{g}^{-1}$ at $\mathrm{CO}_{2}$ partial pressure of $100 \mathrm{kPa}$ and $30{ }^{\circ} \mathrm{C}$ as reported by Kishor et al. ${ }^{30}$ In the second route, PEI and tetraethylenepentamine (TEPA) are the usual modifying reagents. For example, PEI was impregnated into the inner channel of composite 5A@mesoporous silica fabricated via the sol-gel coating procedure as reported by Liu et al. ${ }^{31}$ Besides, the amine containing polymers can also be used as grafted or impregnated amines. For example, the silica gel was grafted or impregnated with acrylamide polymer as reported by Zhao et $a .^{32}$ In the last route, the molecularly imprinted $\mathrm{CO}_{2}$ adsorbents were developed by Zhao et al., using ethanedioic acid as template, acrylamide as functional monomer and ethylene glycol dimethacrylate as cross-linker. ${ }^{28,29}$ Inspired by these reports, the composite support with amine loading would be a feasible strategy for designing amine modified solid composite.

Up to now, amine modified composites for $\mathrm{CO}_{2}$ capture are rarely reported. Herein, an amine impregnated composite strategy was used to fabricate the two series of adsorbents, TEPA-loaded ZSM-5/KIT-6 and PEI-loaded ZSM-5/KIT-6. At the same time, it was found that there are many superiorities in amine impregnated ZSM-5/KIT-6 over the conventional silicabased materials, including high amine loading, high $\mathrm{CO}_{2}$ adsorption capacity, high amine efficiency, rapid kinetics, high enthalpy and high regeneration performance.

\section{Experimental}

\subsection{Preparation of support and amine loaded samples}

ZSM-5/KIT-6 ( $\mathrm{Si} / \mathrm{Al}=50)$ with molar composition of 1 TEOS:0.02 Al:0.017 P123:1.31 BuOH:195 $\mathrm{H}_{2} \mathrm{O}: 1.83 \mathrm{HCl}$ was prepared through an assembly procedure. ${ }^{33}$ First, $8.5 \mathrm{~g}$ of tetraethyl orthosilicate (TEOS, $99 \mathrm{wt} \%$, Aldrich) was gradually dropped into the mixture of $16.87 \mathrm{~g}$ of distilled water, $4.54 \mathrm{~g}$ of tetrapropylammonium hydroxide solution (TPAOH, $25 \mathrm{wt} \%$, Acros Organics) and $0.167 \mathrm{~g}$ of aluminium isopropoxide (AIP, $99.99 \mathrm{wt} \%$, Acros Organics) with vigorous stirring at $35{ }^{\circ} \mathrm{C}$ for $2 \mathrm{~h}$. Then, hydrothermal treatment was performed at $150{ }^{\circ} \mathrm{C}$ for $10 \mathrm{~h}$, giving resultant sample ZSM- $5 \mathrm{~S}_{1}$. Second, $4 \mathrm{~g}$ of $n$-butanol
(BuOH, 99.5 wt\%, Sinopharm Chem. Reagent Co.) was added into P123 solution containing $4 \mathrm{~g}$ of $\mathrm{P} 123\left(\mathrm{EO}_{20} \mathrm{PO}_{70} \mathrm{EO}_{20}, M_{\mathrm{w}}=\right.$ 5800 , Aldrich), $125 \mathrm{~g}$ of distilled water and $7.5 \mathrm{~g}$ of $\mathrm{HCl}(36 \mathrm{wt} \%$, Xilong Chem. Reagent Co.). The mixture was stirred at $35{ }^{\circ} \mathrm{C}$ for $1 \mathrm{~h}$, giving it $\mathrm{S}_{2}$. Third, as cooling to room temperature, $\mathrm{S}_{1}$ was uniformly added to $\mathrm{S}_{2}$, and then stirred at $35{ }^{\circ} \mathrm{C}$ for $24 \mathrm{~h}$ before the hydrothermal process was performed at $100{ }^{\circ} \mathrm{C}$ for $24 \mathrm{~h}$. As cooling to room temperature, the product was filtered, dried at $100{ }^{\circ} \mathrm{C}$ for $24 \mathrm{~h}$ and calcined at $550{ }^{\circ} \mathrm{C}$ for $6 \mathrm{~h}$ with a heating rate of $5{ }^{\circ} \mathrm{C} \mathrm{min}^{-1}$. The as-synthesized composite is denoted as ZK. The mass of precursor solution accounted for $18 \%$ of the mixture. The characterization methods for ZK, such as X-ray diffraction (XRD), nitrogen adsorption/desorption and scanning electron microscopy (SEM) can be seen in our previous study. $^{34}$

TEPA or PEI was introduced into the ZK support by wet impregnation. The typical impregnation step carried out at atmospheric pressure was depicted as follows. A certain amount of TEPA or PEI was dispersed in $25 \mathrm{ml}$ ethanol (Xilong Chem. Reagent Co.) under stirring for $30 \mathrm{~min}$ at room temperature. Subsequently, $0.5 \mathrm{~g}$ of ZK support was added under further stirring for $6.5 \mathrm{~h}$. The ethanol was evaporated and the mixture was dried at $80{ }^{\circ} \mathrm{C}$ in air for $16 \mathrm{~h}$. The samples are referred to ZKTEPA- $X$ or ZK-PEI- $X(X=50,60,70$ or 80$)$, where $X$ stands for mass fraction of TEPA or PEI. For instance, ZK-TEPA-60 indicates that the $\mathrm{ZK}$ is loaded with $60 \%$ TEPA.

A schematic representation of the process for the preparation of ZK-PEI- $X$ or ZK-TEPA- $X$ is shown in Fig. 1.

\subsection{Characterization}

Thermal gravimetric and derivative thermogravimetric analysis (TGA/DTG) was performed on a SDT Q600 TGA (TA, USA) in nitrogen flow up to $800{ }^{\circ} \mathrm{C}$.

Elemental analysis was carried out with a EA 2400 II elemental analyzer (Perkin-Elmer, USA) for nitrogen content of various samples.

Fourier transform infrared spectra (FTIR) were detected with a Nexus 470 IR spectrometer (Nicolet, USA) in wavenumber range of $4000-400 \mathrm{~cm}^{-1}$. Detected wafers were made by mixing the samples and $\mathrm{KBr}$ with a mass ratio of $1: 100$.

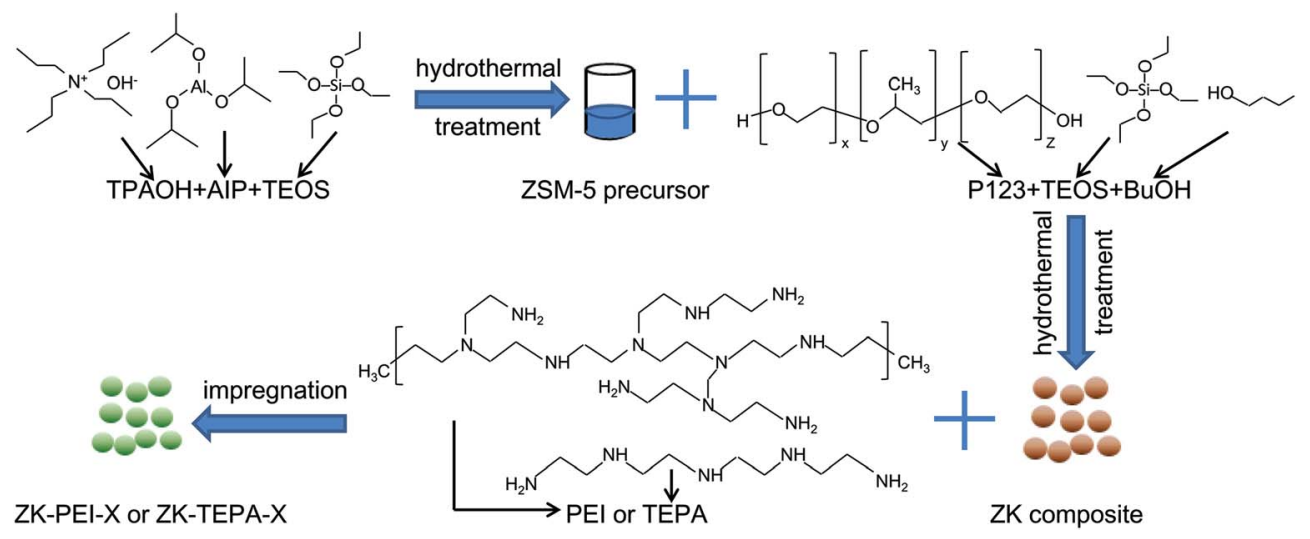

Fig. 1 Schematic representation of the preparation of ZK-PEI-X or ZK-TEPA-X. 
Nitrogen adsorption/desorption tests were carried out at $-196{ }^{\circ} \mathrm{C}$ with a NOVA2000e automatic surface analyzer (Quantachrome, USA). Each sample was outgassed at $100{ }^{\circ} \mathrm{C}$ in nitrogen atmosphere for $8 \mathrm{~h}$ before test. The surface area was calculated by Brunauer-Emmett-Teller (BET). Total pore volume was calculated from $\mathrm{N}_{2}$ adsorption capacity at $P / P_{0}=$ 0.99 .

\section{3. $\mathrm{CO}_{2}$ adsorption}

$\mathrm{CO}_{2}$ adsorption capacity was determined by SDT Q600 TGA (TA, USA) with a scale of $0.1 \mu \mathrm{g}$. In a typical experiment, a certain amount of sample was put in a $0.05 \mathrm{~cm}^{3}$ platinum pan and regenerated (heated up to $110{ }^{\circ} \mathrm{C}$ with a heating rate of $10{ }^{\circ} \mathrm{C} \mathrm{min}{ }^{-1}$ and kept at $110{ }^{\circ} \mathrm{C}$ to get a constant weight) in $\mathrm{N}_{2}$ $\left(100 \mathrm{~cm}^{3} \mathrm{~min}^{-1}\right.$ ) prior to adsorption. Then the sample was cooled to $60{ }^{\circ} \mathrm{C}$ before exposure to the $\mathrm{CO}_{2} / \mathrm{N}_{2}$ mixed gases $\left(15\right.$ vol\% $\mathrm{CO}_{2}$ ) until the quantity of sample displayed no noticeable changes. The weight change and heat flow of amine modified ZK versus time were recorded. The adsorption capacity was calculated according to the following equation (eqn (1)) and enthalpy was calculated from the heat flow versus time and dry mass of sample according to the following equation (eqn (2)):

$$
\begin{gathered}
q_{\mathrm{e}}=\frac{\left(m_{\mathrm{e}}-m_{\mathrm{d}}\right) / 44.01}{m_{\mathrm{d}} / 1000} \\
H_{\mathrm{ads}}=\frac{44.01 \varphi t}{1000 m_{\mathrm{d}}}
\end{gathered}
$$

where $q_{\mathrm{e}}$ is the equilibrium adsorption capacity of $\mathrm{CO}_{2}$ $\left(\mathrm{mmol} \mathrm{g}{ }^{-1}\right), m_{\mathrm{e}}$ and $m_{\mathrm{d}}$ are the sample weights after equilibrium and dehydration (mg), respectively, $H_{\text {ads }}$ is the enthalpy $\left(\mathrm{kJ} \mathrm{mol}^{-1}\right)$, $\varphi$ is the heat flow ( $\mathrm{mW}), t$ is the time versus heat flow (s).

The $\mathrm{CO}_{2}$ saturated sample was regenerated in the same procedure as described above before adsorption was carried out at $60^{\circ} \mathrm{C}$. Thus, the cyclic performance during five recycles was explored.

\section{Results and discussion}

\subsection{Characterization}

TGA weight loss curves of ZK loaded with various amounts of TEPA and PEI are shown in Fig. 2a, and the corresponding DTG curves are shown in Fig. 2b. All samples exhibited original weight losses below $120{ }^{\circ} \mathrm{C}$ due to liberation of moisture and $\mathrm{CO}_{2}$. The further remarkable weight loss emerged in the range of $125-400{ }^{\circ} \mathrm{C}$ for samples of TEPA-loaded ZK, and $190-400{ }^{\circ} \mathrm{C}$ for samples of PEI-loaded ZK. ZK-TEPA-50 displayed an maximum weight loss rate at $217^{\circ} \mathrm{C}$ while $303{ }^{\circ} \mathrm{C}$ for ZK-PEI-50, which can be associated with the decomposition of TEPA and PEI, respectively. With the increase of the amine loadings, the sharp weight loss peak shifted slightly towards the higher temperature for both TEPA-loaded and PEI-loaded samples. The introduction of more TEPA or PEI into the nanoporous support increased the particle size of the sample, resulting in the increase of decomposition temperature. ${ }^{35}$ Besides, higher decomposition temperatures for PEI-loaded samples than TEPA-loaded samples indicated that the thermal stability was enhanced as the amine molecular weight increased. In this stage, the weight losses of about $45.3 \%, 57.53 \%, 67.42 \%$ and $72.99 \%$ were obtained for ZK-TEPA-50, ZK-TEPA-60, ZK-TEPA-70 and ZK-TEPA-80, respectively. The actual amine contents were very close to the theoretical values, indicating that TEPA was loaded well onto the support during the impregnation process. While ZK-PEI-50, ZK-PEI-60, ZK-PEI-70 and ZK-PEI-80 showed the smaller weight losses of about $39.23 \%, 51.25 \%, 63.49 \%$ and $76.71 \%$, respectively. It can be ascribed to the larger amine molecular size and viscosity of PEI. PEI with large molecular size is not easy to enter the support and its large viscosity made the agglomeration occur more easily. As temperature exceeded $400{ }^{\circ} \mathrm{C}$, there was no obvious weight loss and the different remaining weights were observed at $800{ }^{\circ} \mathrm{C}$. It was due to the high heat resistant silica existing in the molecular sieve framework. ZK loaded with TEPA and PEI displayed thermal stability in $\mathrm{N}_{2}$ up to 125 and $190{ }^{\circ} \mathrm{C}$, respectively, which indicated that the regeneration temperature of $110{ }^{\circ} \mathrm{C}$ was suitable for the cyclic adsorption/desorption on all the samples.

The amount of amine groups impregnated in the ZK can also be determined by elemental analysis. Nitrogen contents in ZK modified with TEPA or PEI are listed in Table 1 . When amine loading increased from 50 to $80 \%$, the nitrogen contents increased from 12.06 to $20.46 \mathrm{mmol} \mathrm{g}^{-1}$ for TEPA-loaded

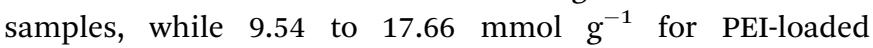
samples, which were in close agreement with TGA results.
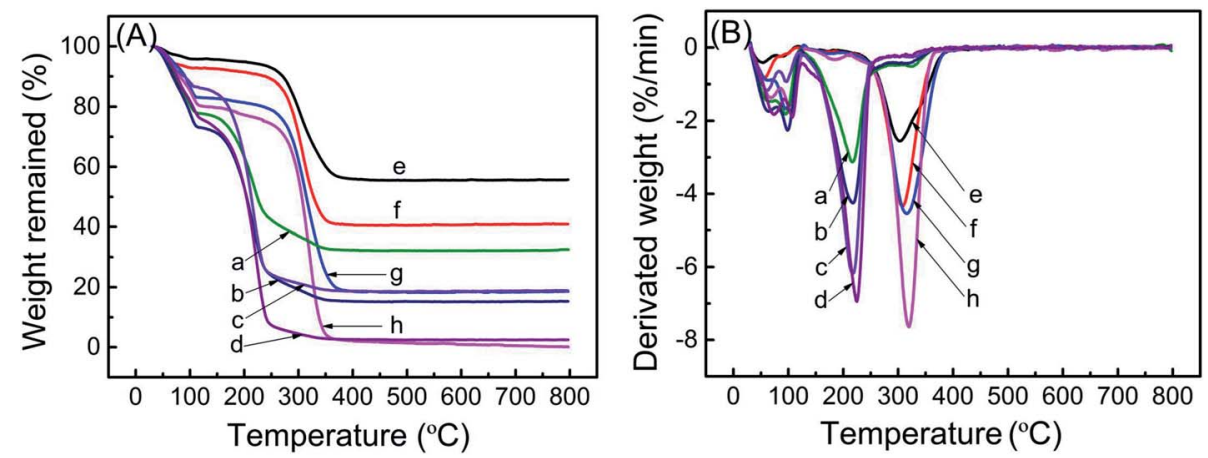

Fig. 2 (A) TGA curves and (B) DTG curves of (a) ZK-TEPA-50, (b) ZK-TEPA-60, (c) ZK-TEPA-70, (d) ZK-TEPA-80, (e) ZK-PEI-50, (f) ZK-PEI-60, (g) ZK-PEI-70 and (h) ZK-PEI-80. 
Table 1 Textural properties, nitrogen contents, $\mathrm{CO}_{2}$ adsorption capacities and amine efficiencies of amine modified $\mathrm{ZK}$ adsorbents at $60{ }^{\circ} \mathrm{C}$

\begin{tabular}{llllll}
\hline Adsorbent & $S_{\text {BET }}\left(\mathrm{m}^{2} \mathrm{~g}^{-1}\right)$ & $V_{\text {total }}\left(\mathrm{cm}^{3} \mathrm{~g}^{-1}\right)$ & $\begin{array}{l}\text { Nitrogen content } \\
\left(\mathrm{mmol} \mathrm{g}^{-1}\right)\end{array}$ & $\begin{array}{l}\text { Capacity } \\
\left(\mathrm{mmol} \mathrm{g}^{-1}\right)\end{array}$ & $\begin{array}{l}\text { Amine efficiency } \\
\left(\mathrm{mmol} \mathrm{CO}_{2} / \mathrm{mmol} \mathrm{N}^{2}\right.\end{array}$ \\
\hline ZK-PEI-50 & 73.2 & 0.20 & 9.54 & 3.24 & 0.34 \\
ZK-PEI-60 & 23.9 & 0.08 & 12.89 & 4.49 & 0.35 \\
ZK-PEI-70 & 9.7 & 0.03 & 15.02 & 3.93 & 0.26 \\
ZK-PEI-80 & - & - & 17.66 & 2.91 & 0.16 \\
ZK-TEPA-50 & 94.3 & 0.25 & 12.06 & 4.27 & 0.35 \\
ZK-TEPA-60 & 40.9 & 0.09 & 14.03 & 5.32 & 0.38 \\
ZK-TEPA-70 & 30.8 & 0.07 & 16.19 & 4.85 & 0.30 \\
ZK-TEPA-80 & - & - & 20.46 & 4.76 & 0.23
\end{tabular}

The FTIR spectra of ZK support, TEPA-loaded ZK and PEIloaded ZK are shown in Fig. 3. The characteristic bands of KIT-6 around 1096, 802 and $459 \mathrm{~cm}^{-1}$ were identified over all the samples due to $\mathrm{Si}-\mathrm{O}-\mathrm{Si}$ asymmetric, symmetric stretching and bending vibrations, respectively. ${ }^{36-38}$ While the band at $544 \mathrm{~cm}^{-1}$ associated with typical vibration modes of ZSM-5 (fivemembered rings of $\mathrm{T}-\mathrm{O}-\mathrm{T}, \mathrm{T}=\mathrm{Si}$ or $\mathrm{Al}$ ) in $\mathrm{ZK}$ shifted slightly towards the higher wavenumbers as shown in the spectra of ZKTEPA-60 and ZK-PEI-60. The bands at 3467, 1638 and $967 \mathrm{~cm}^{-1}$ were associated with $\mathrm{O}-\mathrm{H}$ stretching vibration of silanol groups, $\mathrm{H}-\mathrm{O}-\mathrm{H}$ bend, and $\mathrm{Si}-\mathrm{O}$ stretching vibration of free silanol groups, respectively. ${ }^{39,40}$ After TEPA or PEI impregnation, these bands either got weakened or eliminated entirely, which indicated that a part amount of amine groups in TEPA or PEI can interact with free silanol groups in ZK. The relevant reaction equations are given as follows:

$$
\begin{aligned}
& \mathrm{Si}-\mathrm{OH}+\mathrm{RNH}_{2} \rightarrow \mathrm{Si}-\mathrm{O}^{-} \mathrm{N}^{+} \mathrm{H}_{3} \mathrm{R} \\
& \mathrm{Si}-\mathrm{OH}+\mathrm{R}_{2} \mathrm{NH} \rightarrow \mathrm{Si}-\mathrm{O}^{-} \mathrm{N}^{+} \mathrm{H}_{2} \mathrm{R}_{2}
\end{aligned}
$$

Besides the elimination of the band of free silanol groups, some new bands around 2956, 2854, 1634, 1573, 1481 and $1320 \mathrm{~cm}^{-1}$ appeared after TEPA or PEI loading in ZK. The bands around 2956 and $2854 \mathrm{~cm}^{-1}$ were associated with $\mathrm{C}-\mathrm{H}$ asymmetric and symmetric stretching vibrations, while the band around $1481 \mathrm{~cm}^{-1}$ was associated with $\mathrm{C}-\mathrm{H}$ deformation. ${ }^{41,42} \mathrm{~A}$ weak band around $1634 \mathrm{~cm}^{-1}$ was found, related to $\mathrm{N}-\mathrm{H}$

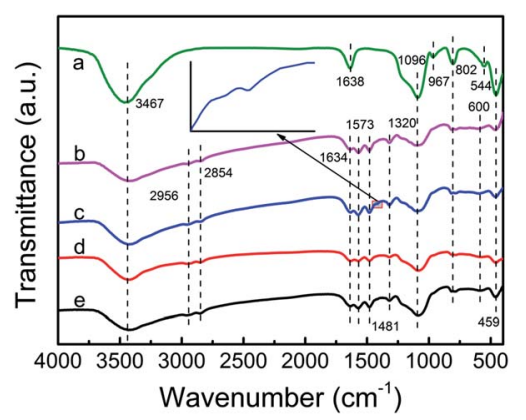

Fig. 3 FTIR spectra of (a) ZK, (b) ZK-TEPA-60, (c) ZK-TEPA-60 after $\mathrm{CO}_{2}$ adsorption, (d) ZK-PEI-60 and (e) ZK-PEI-60 after $\mathrm{CO}_{2}$ adsorption. deformation of protonated primary amine groups $\left(\mathrm{Si}-\mathrm{O}-\mathrm{N}^{+} \mathrm{H}_{3} \mathrm{R}\right)$ or secondary amine groups $\left(\mathrm{Si}-\mathrm{O}-\mathrm{N}^{+} \mathrm{H}_{2} \mathrm{R}_{2}\right)$ formed through reactions in eqn (3) and (4). The bands around 1573 and $1319 \mathrm{~cm}^{-1}$ were respectively associated with $\mathrm{N}-\mathrm{H}$ deformation of primary amine groups and $\mathrm{C}-\mathrm{N}$ stretching vibration. ${ }^{\mathbf{4 2 4 3}}$ The spectra of ZK-TEPA-60 and ZK-PEI-60 after $\mathrm{CO}_{2}$ adsorption are also included in Fig. 3. A new band at $1415 \mathrm{~cm}^{-1}$ was identified in both spectra, attributed to NCOO skeletal vibration of carbamate formed from the reactions between amine groups and $\mathrm{CO}_{2}$ molecules. These reactions that may occur during $\mathrm{CO}_{2}$ adsorption process are depicted as follows:

$$
\begin{gathered}
\mathrm{CO}_{2}+2 \mathrm{RNH}_{2} \rightarrow \mathrm{RNHCOO}^{-}+\mathrm{RNH}_{3}^{+} \\
\mathrm{CO}_{2}+2 \mathrm{R}_{1} \mathrm{R}_{2} \mathrm{NH} \rightarrow \mathrm{R}_{1} \mathrm{R}_{2} \mathrm{NCOO}^{-}+\mathrm{R}_{1} \mathrm{R}_{2} \mathrm{NH}_{2}^{+} \\
\mathrm{CO}_{2}+\mathrm{R}_{2} \mathrm{NH}+\mathrm{RNH}_{2} \rightarrow \\
\mathrm{R}_{2} \mathrm{NCOO}^{-}+\mathrm{RNH}_{3}^{+}\left(\text {or } \mathrm{RNHCOO}^{-}+\mathrm{R}_{2} \mathrm{NH}_{2}^{+}\right. \text {) }
\end{gathered}
$$

The $\mathrm{N}_{2}$ adsorption/desorption isotherms of TEPA-loaded ZK and PEI-loaded ZK belonging to type IV isotherms are shown in Fig. 4, while the textural properties such as specific surface area $\left(S_{\mathrm{BET}}\right)$ and total pore volume $\left(V_{\text {total }}\right)$ were listed in Table 1 . When amine loading increased from 50 to $70 \%$, the value of $S_{\mathrm{BET}}$ decreased from 73.2 to $9.7 \mathrm{~m}^{2} \mathrm{~g}^{-1}$ for PEI-loaded samples, while 94.3 to $30.8 \mathrm{~m}^{2} \mathrm{~g}^{-1}$ for TEPA-loaded samples. Similarly, the value of $V_{\text {total }}$ decreased from 0.20 to $0.03 \mathrm{~cm}^{3} \mathrm{~g}^{-1}$ for PEI-loaded samples, while 0.25 to $0.07 \mathrm{~cm}^{3} \mathrm{~g}^{-1}$ for TEPA-loaded samples.

\section{2. $\mathrm{CO}_{2}$ adsorption}

The $\mathrm{CO}_{2}$ adsorption curves of $\mathrm{ZK}$ loaded with various amounts of TEPA and PEI with an adsorption temperature of $60{ }^{\circ} \mathrm{C}$ are shown in Fig. 5a and b, respectively. The adsorption data is given in Table 1 . When amine loading was 50\%, ZK-TEPA-50 demonstrated an appreciable adsorption capacity of $4.27 \mathrm{mmol} \mathrm{g}^{-1}$, whereas ZK-PEI-50 demonstrated that of $3.24 \mathrm{mmol} \mathrm{g}^{-1}$. The maximum values in the two series were 5.32 and $4.49 \mathrm{mmol} \mathrm{g}^{-1}$ for ZK-TEPA-60 and ZK-PEI-60, respectively. The increase of adsorption capacity was due to the increased nitrogen content and the enhanced chemisorption between amine groups and $\mathrm{CO}_{2}$ (Table 1, Fig. 5). Despite the reduction of physisorption due to the decrease of surface area and pore volume, the enhanced chemisorption due to the increase of nitrogen content may be dominant in the $\mathrm{CO}_{2}$ adsorption, 


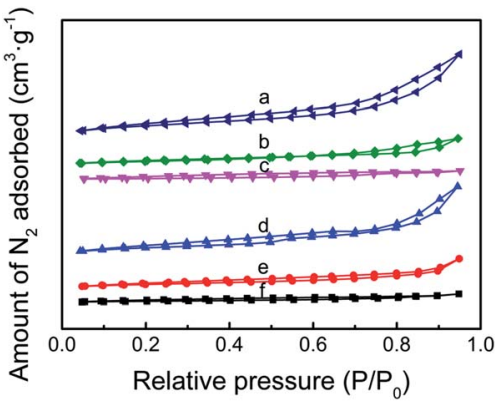

Fig. 4 (A) $\mathrm{N}_{2}$ adsorption/desorption isotherms of (a) ZK-TEPA-50, (b) ZK-TEPA-60, (c) ZK-TEPA-70, (d) ZK-PEI-50, (e) ZK-PEI-60 and (f) ZKPEI-70.

resulting in the increase of adsorption capacity (Table 1, Fig. 5). Increasing amine loading to $70 \%$, the capacity decreased to $4.85 \mathrm{mmol} \mathrm{g}^{-1}$ for ZK-TEPA-70 and $3.93 \mathrm{mmol} \mathrm{g}^{-1}$ for ZK-PEI-70. Further increasing amine loading to $80 \%$, the value decreased to $4.76 \mathrm{mmol} \mathrm{g}^{-1}$ for ZK-TEPA-80, but ZK-PEI-80 demonstrated an apparent decrease in uptake of $2.91 \mathrm{mmol} \mathrm{g}^{-1}$. Mesoporous structure of KIT-6 in the composites offered large space and channel for the loading of amine groups as well as $\mathrm{CO}_{2}$ diffusion and the microporous structure of ZSM-5 in the composites played a major role in physisorption of $\mathrm{CO}_{2}$. Although the nitrogen contents in the two series increased significantly as amine loadings were increased to $70 \%$, this property could not compensate for the great losses of surface area as well as pore volume (Table 1). The high loading of amines blocked the ZSM-5 pores and limited the diffusion of $\mathrm{CO}_{2}$ to ZSM-5 channels and to the active adsorption sites on amine groups, resulting in the lower adsorption capacities compared to the maximum values.

On the other hand, TEPA-loaded samples displayed higher $\mathrm{CO}_{2}$ adsorption capacities compared to those of corresponding PEI-loaded samples. For ZK-TEPA- $X$, TEPA was well dispersed in the inner channels of composites even at high loading of $60 \%$ while retaining a pore volume of $0.09 \mathrm{~cm}^{3} \mathrm{~g}^{-1}$ as well as a surface area of $40.9 \mathrm{~m}^{2} \mathrm{~g}^{-1}$, because of its low molecular weight and linear properties (Table 1). These common effects were beneficial to the improvement of adsorption capacity due to the easiness for $\mathrm{CO}_{2}$ to overcome the diffusion resistance and access to the active sites. For ZK-PEI- $X$, due to the high molecular weight and polymeric properties of PEI, the dispersion of PEI in composites was low and the significant losses of pore volume and surface area were found (Table 1). These effects caused damage to the accessibility of PEI and resulted in the lower adsorption capacities compared to those of ZK-TEPA- $X$. It can be concluded that the amine content (nitrogen content) and the accessibility of active sites on amine groups to interact with $\mathrm{CO}_{2}$ are the important factors for the efficient use of an adsorbent in $\mathrm{CO}_{2}$ capture.

In addition, the amine efficiency of the adsorbents calculated from the ratio between $\mathrm{CO}_{2}$ capture capacity and nitrogen content are given in Table $1 . \mathrm{CO}_{2}$ adsorption capacity and amine efficiency with amine loading for ZK-TEPA- $X$ and ZK-PEI- $X$ are shown in Fig. 6a and b, respectively. The reaction between $\mathrm{CO}_{2}$
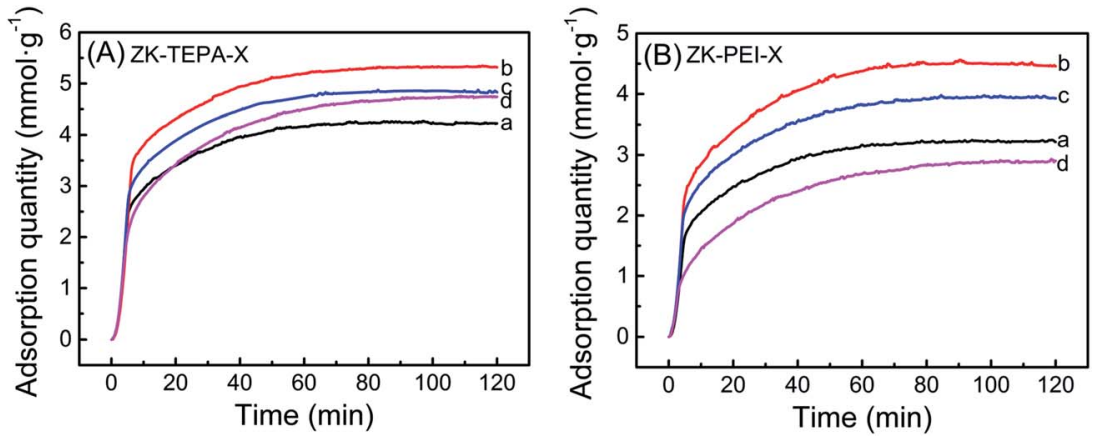

Fig. 5 (A) $\mathrm{CO}_{2}$ adsorption curves of (a) ZK-TEPA-50, (b) ZK-TEPA-60, (c) ZK-TEPA-70 and (d) ZK-TEPA-80 and (B) $\mathrm{CO}_{2}$ adsorption curves of (a) ZK-PEI-50, (b) ZK-PEI-60, (c) ZK-PEI-70 and (d) ZK-PEI-80 (adsorption at $60{ }^{\circ} \mathrm{C}$, inlet $\mathrm{CO}_{2}$ concentration: 15 vol\%, gas flow rate: $60 \mathrm{~cm}^{3}$ min ${ }^{-1}$ ).
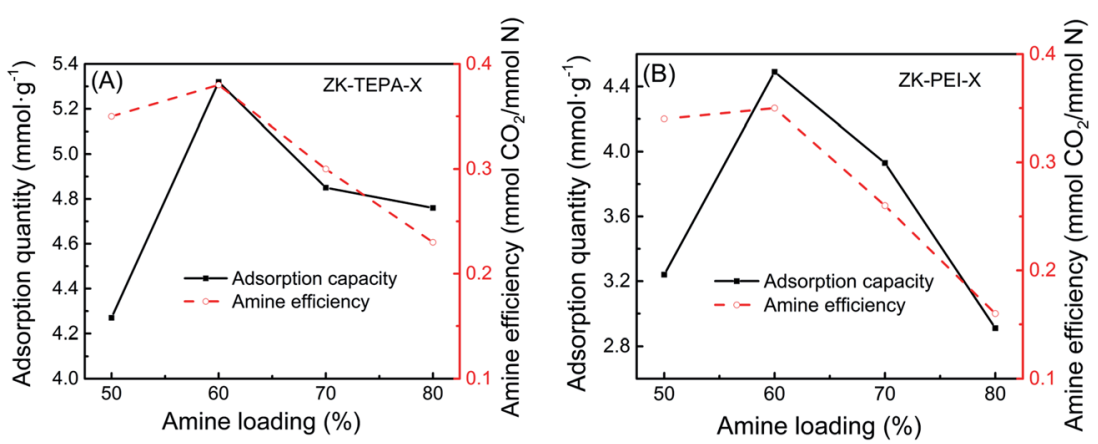

Fig. $6 \mathrm{CO}_{2}$ adsorption capacity and amine efficiency with amine loading for (A) ZK-TEPA-X and (B) ZK-PEI-X. 
and amine groups needs two amine groups per $\mathrm{CO}_{2}$ molecule (eqn (4)-(6)), so the amine efficiency should not exceed 0.5 normally. ${ }^{44}$ The similar trends were observed in both series. The amine efficiency increased first and then decreased with the increase of amine loadings. ZK-TEPA-60 displayed an maximum amine efficiency of 0.38 , which was higher than that of ZK-PEI$60(0.35)$.

The adsorption temperature is an important factor for chemisorption of $\mathrm{CO}_{2}$, so the effects of various temperatures $\left(30,45,60,75\right.$ and $\left.90{ }^{\circ} \mathrm{C}\right)$ on adsorption capacities of ZK-TEPA60 and ZK-PEI-60 were investigated as shown in Fig. 7a and b, respectively. For ZK-TEPA-60, the adsorption capacity increased in the temperature range of $30-60{ }^{\circ} \mathrm{C}$ while decreased in range of $60-90^{\circ} \mathrm{C}$. The similar trend was observed for ZK-PEI- 60 while the optimum temperature of ZK-PEI-60 $\left(75^{\circ} \mathrm{C}\right)$ shifted towards a higher value compared to that of ZK-TEPA-60 $\left(60{ }^{\circ} \mathrm{C}\right)$, which may be due to the different natures of TEPA and PEI molecules. The increase in adsorption capacity at the first temperature period indicated the dominant contribution of chemisorption for $\mathrm{CO}_{2}$ adsorption capacity, which was based on two reasons. One reason is that the $\mathrm{CO}_{2}$ molecule overcame the kinetic limitation and the faster diffusion of $\mathrm{CO}_{2}$ molecule was achieved at higher temperatures. Another reason is that the TEPA and PEI molecules were more flexible and their dispersions were more uniform in the mesopores, and more active

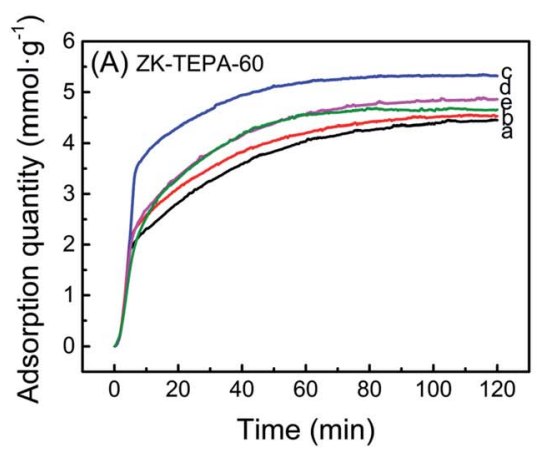

adsorption sites on amine groups were exposed to $\mathrm{CO}_{2}$ molecules at higher temperatures.

The capacity decreased at the second temperature period. The adsorption progress was dependent on thermodynamics at relatively high temperatures. At this period, $\mathrm{CO}_{2}$ molecules were activated with slightly higher kinetic energy and the part of them overcame the chemical bonds and van der Waals' force between the surface of ZK-TEPA-60 or ZK-PEI-60 and $\mathrm{CO}_{2}$ molecules. The adsorption capacities of ZK-TEPA-60 at 30, 45, 60,75 and $90{ }^{\circ} \mathrm{C}$ were, 4.44, 4.53, 5.32, 4.85 and $4.62 \mathrm{mmol} \mathrm{g}^{-1}$, respectively, while $3.85,3.95,4.49,4.59$ and $4.43 \mathrm{mmol} \mathrm{g}^{-1}$ for ZK-PEI-60. Their adsorption capacities are all higher than $3 \mathrm{mmol} \mathrm{g}^{-1}$, especially for ZK-TEPA-60, indicating that both ZKTEPA-60 and ZK-PEI-60 are potentially efficient sorbents for $\mathrm{CO}_{2}$ capture.

A comparison of $\mathrm{CO}_{2}$ adsorption capacity via various amine modified adsorbents is given in Table 2. Under similar conditions, both ZK-TEPA-60 and ZK-PEI-60 obtained in this work displayed outstanding adsorption capacities at a low $\mathrm{CO}_{2}$ partial pressure.

What's more, in the practical adsorption operation, the adsorption kinetics should be carefully taken into account. In this work, the adsorption time was selected to achieve 50 and $85 \%$ of the equilibrium adsorption capacities for the two best samples in the two series (ZK-TEPA-60 and ZK-PEI-60) at three temperatures as shown in Fig. 8 and Table 3. At 30 and $90{ }^{\circ} \mathrm{C}$,

Fig. $7 \mathrm{CO}_{2}$ adsorption curves of (A) ZK-TEPA-60 and (B) ZK-PEI-60 at (a) $30{ }^{\circ} \mathrm{C}$, (b) $45^{\circ} \mathrm{C}$, (c) $60{ }^{\circ} \mathrm{C}$, (d) $75^{\circ} \mathrm{C}$ and (e) $90{ }^{\circ} \mathrm{C}$ (inlet $\mathrm{CO} 2$

concentration: 15 vol\%, gas flow rate: $60 \mathrm{~cm}^{3} \mathrm{~min}^{-1}$ ).

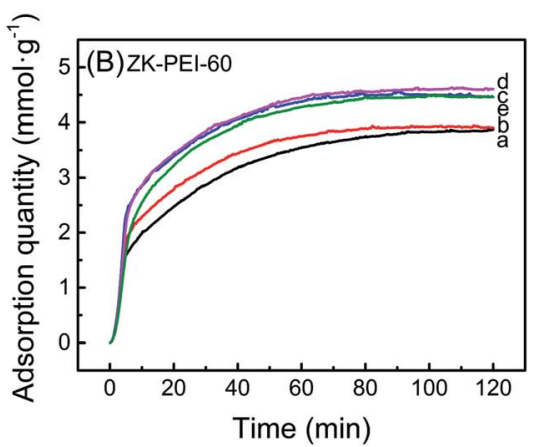

Table $2 \mathrm{CO}_{2}$ adsorption capacities of various adsorbents from literatures and our work ${ }^{a}$

\begin{tabular}{llllll}
\hline Support & Modifier & $W_{\mathrm{t}}(\%)$ & Condition & Capacity $\left(\mathrm{mmol} \mathrm{g}^{-1}\right)$ & Method \\
\hline Y60 & TEPA & 50 & $60^{\circ} \mathrm{C} / 15 \mathrm{kPa}$ & 2.56 & Grafting \\
SBA-16 & AEAPS & 15 & $60^{\circ} \mathrm{C} / 15 \mathrm{kPa}$ & 0.73 & Grafting \\
ZSM-5 & PEI & 33.3 & $40^{\circ} \mathrm{C} / 101 \mathrm{kPa}$ & 2.64 & 45 \\
ZSM-5 & TEPA & 50 & $25^{\circ} \mathrm{C} / 20 \mathrm{kPa}$ & 0.98 & Impregnation \\
KIT-6 & PEI & 50 & $75^{\circ} \mathrm{C} / 101 \mathrm{kPa}$ & 3.07 & Impregnation \\
KIT-6 & TEPA & 50 & $60^{\circ} \mathrm{C} / 10 \mathrm{kPa}$ & 2.85 & 48 \\
5A@MSA & PEI & 30 & $25^{\circ} \mathrm{C} / 15 \mathrm{kPa}$ & 1.63 & Impregnation \\
ZSM-5/KIT-6 & TEPA & 60 & $60^{\circ} \mathrm{C} / 15 \mathrm{kPa}$ & 5.32 & Impregnation \\
ZSM-5/KIT-6 & PEI & 60 & $60^{\circ} \mathrm{C} / 15 \mathrm{kPa}$ & 4.49 & Impregnation \\
\end{tabular}

${ }^{a} W_{\mathrm{t}}$ : weight percent of modifiders. Condition: pressure was the $\mathrm{CO}_{2}$ partial pressure with dry condition. Y60: Y-type zeolite with a Si/Al molar ratio of 60. AEAPS: $N$-(2-aminoethyl)-3-aminopropyltrimethoxysilane. 5A@MSA: 5A@MSA was combined with 5A zeolite and mesoporous silica. 

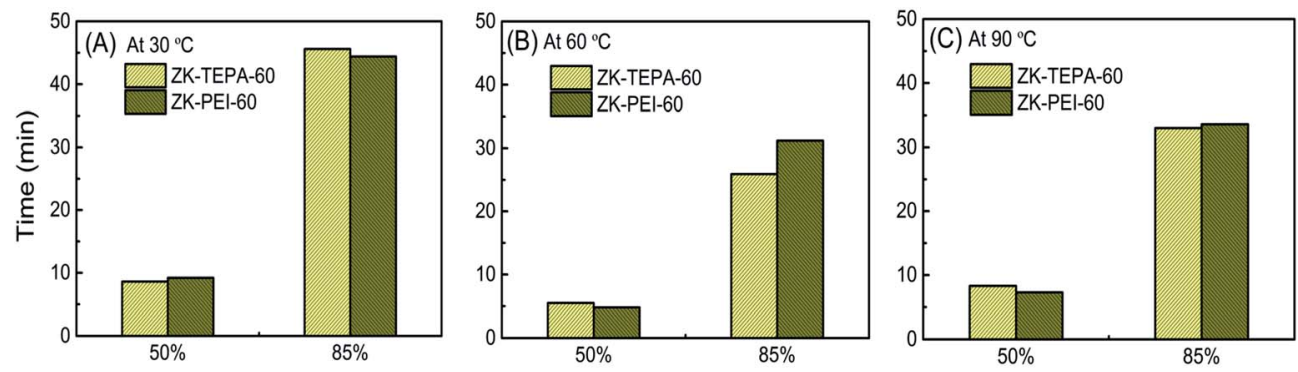

Percentage of maximum adsorption capacity (\%)

Fig. 8 Adsorption time of ZK-TEPA-60 and ZK-PEI-60 at (A) $30{ }^{\circ} \mathrm{C}$, (B) $60{ }^{\circ} \mathrm{C}$ and (C) $90{ }^{\circ} \mathrm{C}$ using $15 \% \mathrm{CO}_{2}$.

Table 3 Adsorption kinetics and enthalpies of ZK-PEI-60 and ZK-TEPA-60 at three different temperatures

\begin{tabular}{|c|c|c|c|c|c|}
\hline Adsorbent & Temperature $\left({ }^{\circ} \mathrm{C}\right)$ & $50 \%$ & $85 \%$ & Enthalpy $\left(\mathrm{kJ} \mathrm{mol}^{-1}\right)$ & Average enthalpy $\left(\mathrm{kJ} \mathrm{mol}^{-1}\right)$ \\
\hline ZK-PEI-60 & 30 & 9.2 & 44.4 & 67.3 & 70 \\
\hline \multirow[t]{3}{*}{ ZK-TEPA-60 } & 30 & 8.6 & 45.6 & 71.2 & 75.2 \\
\hline & 60 & 5.5 & 25.9 & 81.2 & \\
\hline & 90 & 8.3 & 33 & 73.3 & \\
\hline
\end{tabular}

both samples displayed small differences in time to achieve 50 and $85 \%$ of the maximum adsorption capacities, indicating the similar kinetics. At 30 and $90{ }^{\circ} \mathrm{C}$, respectively, ZK-TEPA-60 required 45.6 and 33 minutes and ZK-PEI-60 required 44.4 and 33.6 minutes to achieve $85 \%$ of the maximum adsorption capacities (Table 3, Fig. 8). While at $60{ }^{\circ} \mathrm{C}$, the differences in time to achieve $85 \%$ of the maximum adsorption capacities were obvious between both samples (25.9 minutes for ZK-TEPA60 and 31.2 minutes for ZK-PEI-60) (Table 3, Fig. 8). Therefore, TEPA-loaded samples displayed better kinetics than PEI-loaded samples. Normally, more time is required to adsorb additional $\mathrm{CO}_{2}$ to reach high adsorption capacity, while ZK-TEPA-60, which possesses higher $\mathrm{CO}_{2}$ adsorption capacity, interestingly, has better kinetics. This result was due to the well dispersion of
TEPA molecules in the inner channels of composites for the easy diffusion of $\mathrm{CO}_{2}$ molecules, suggesting the importance of uniform dispersion of amine molecules for enhanced kinetics.

The heat of adsorption, usually defined as the enthalpy $\left(H_{\mathrm{ads}}\right)$ of adsorption, was obtained by calorimetric heat flow measurement for further characterization of adsorption. The differential scanning calorimetry (DSC) heat flow curves of ZK-TEPA-60 and ZK-PEI-60 at three different temperatures are shown in Fig. 9. The enthalpies of adsorption are given in Table 3. The adsorption enthalpies of ZK-TEPA-60 at 30, 60 and $90^{\circ} \mathrm{C}$ were, $71.2,81.2$ and $73.3 \mathrm{~kJ} \mathrm{~mol}^{-1}$, respectively, while 67.3 , 71.9 and $70.9 \mathrm{~kJ} \mathrm{~mol}^{-1}$ for ZK-PEI-60. These values were all higher than $60 \mathrm{~kJ} \mathrm{~mol}^{-1}$, which were consistent with the chemisorption mechanism, revealing the dominance of
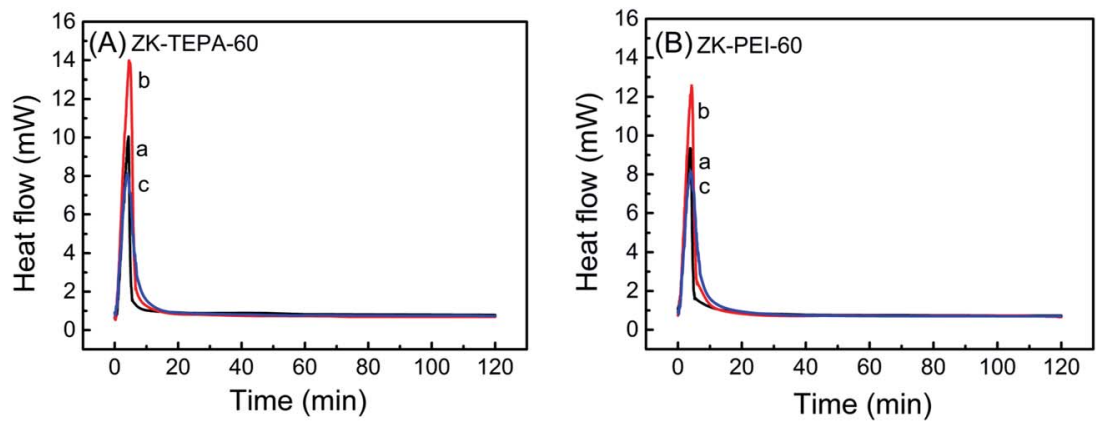

Fig. 9 DSC heat flow curves of (A) ZK-TEPA-60 and (B) ZK-PEI-60 at (a) $30{ }^{\circ} \mathrm{C}$, (b) $60{ }^{\circ} \mathrm{C}$ and (c) $90{ }^{\circ} \mathrm{C}$ using $15 \% \mathrm{CO}_{2}$. 


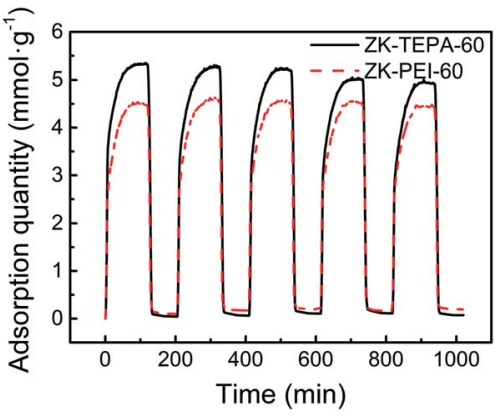

Fig. 10 Cyclic adsorption/desorption runs of ZK-TEPA-60 and ZKPEI-60 (adsorption at $60^{\circ} \mathrm{C}$, desorption at $110^{\circ} \mathrm{C}$, nitrogen flow rate: $100 \mathrm{~cm}^{3} \mathrm{~min}^{-1}$, gas flow rate: $60 \mathrm{~cm}^{3} \mathrm{~min}^{-1}$ ).

chemisorption during the $\mathrm{CO}_{2}$ adsorption process. ${ }^{50}$ These values correlated well with previously reported data. ${ }^{51,52}$ The average enthalpy of $75.2 \mathrm{~kJ} \mathrm{~mol}^{-1}$ was obtained for ZK-TEPA-60 and $70 \mathrm{~kJ} \mathrm{~mol}^{-1}$ for ZK-PEI-60, both of which were slightly larger than the values obtained by Knowles et al. for aminopropylfunctionalized silica gel. ${ }^{52}$ These differences can be associated with various natures of amines. For both samples, the trends on enthalpies are similar to those on adsorption capacities and the high enthalpies suggest the high strength of $\mathrm{CO}_{2}$-amine interaction (Fig. 7).

Apart from high adsorption capacity, the stability and reproducibility of adsorbents are also essential for the sustainable application process. ZK-TEPA-60 and ZK-PEI-60 were selected for the five cyclic $\mathrm{CO}_{2}$ adsorption/desorption studies. The graphs of five cycles for ZK-TEPA-60 and ZK-PEI60 are shown in Fig. 10. After the five cycles, ZK-PEI-60 displayed a stable capacity of $4.45 \mathrm{mmol} \mathrm{g}^{-1}$, which was similar to the initial one ( $\left.4.49 \mathrm{mmol} \mathrm{g}^{-1}\right)$. However, a relatively large drop of $7 \%$ in adsorption capacity occurred for ZK-TEPA-60, compared to that of ZK-PEI-60 (less than 1\%), which may be attributed to the partial volatilization of TEPA in desorption step. ZK-PEI-60 has a better stability and reproducibility than ZK-TEPA-60 during 5 cyclic adsorption/desorption process. But obviously, ZK-TEPA-60 still displayed a large capacity of $4.94 \mathrm{mmol} \mathrm{g}^{-1}$ in the 5 th cycle, which is still higher than the reported data as listed in Table 2 . The stability of ZK-TEPA-60 is comparable to that of TEPA modified MCM-41 (8.5\% drop in adsorption capacity after 6 cycles) reported by Yue et al. ${ }^{53}$ These results suggest that both ZK-TEPA-60 and ZK-PEI60 are good $\mathrm{CO}_{2}$ adsorbents and the latter may be the more promising one. Besides, water vapor also exists in flue gas and the $\mathrm{CO}_{2}$ uptake may be enhanced due to the existence of appropriate content of water vapor. ${ }^{54,55}$ The effect of water vapor will be reported in the future.

\section{Conclusions}

The ZSM-5/KIT-6 support was modified with amines (TEPA or PEI) by wet impregnation. The amine efficiency, kinetics of adsorption, enthalpy of adsorption, stability of adsorbent, reusability of adsorbent, the effect of TEPA or PEI loading as well as temperature on $\mathrm{CO}_{2}$ adsorption performance were investigated. ZK-TEPA-60 displayed the maximum adsorption capacity at $60{ }^{\circ} \mathrm{C}$ while a lower value for ZK-PEI-60 was obtained (5.32 $\mathrm{mmol} \mathrm{g}^{-1}$ vs. $4.49 \mathrm{mmol} \mathrm{g}^{-1}$ ) because of higher nitrogen content and better texture properties. The amine efficiency was up to 0.38 and 0.35 for ZK-TEPA-60 and ZK-PEI-60, respectively. The optimum temperature was $60{ }^{\circ} \mathrm{C}$ for ZK-TEPA-60 while $75{ }^{\circ} \mathrm{C}$ for ZK-PEI-60 (with a capacity of $4.59 \mathrm{mmol} \mathrm{g}^{-1}$ ), probably associated with different natures of amine molecules. ZK-TEPA60 has better kinetics than ZK-PEI-60 due to the well dispersion of TEPA molecules. Higher average enthalpy was obtained for ZK-TEPA-60 (75.2 $\mathrm{kJ} \mathrm{mol}^{-1}$ ) compared to that of ZK-PEI-60 (70 $\mathrm{kJ} \mathrm{mol}^{-1}$ ), suggesting the high strength of $\mathrm{CO}_{2}$-amine interaction. ZK-PEI-60 has a better stability and reproducibility than ZK-TEPA-60 during five cyclic adsorption/desorption process.

\section{Conflicts of interest}

There are no conflicts of interest to declare.

\section{Acknowledgements}

The authors sincerely acknowledge the supports of National Natural Science Foundation of China (No. 51566003) and Natural Science Foundation of Guangxi Province (No. 2015GXNSFAA139231).

\section{References}

1 S. Choi, J. H. Drese and C. W. Jones, ChemSusChem, 2009, 2, 796-854.

2 D. W. Keith, Science, 2009, 325, 1654.

3 M. G. Plaza, C. Pevida, B. Arias, M. D. Casal, C. F. Martín, J. Fermoso, F. Rubiera and J. J. Pis, J. Environ. Eng., 2009, 135, 426-432.

4 C. Pevida, M. G. Plaza, B. Arias, J. Fermoso, F. Rubiera and J. J. Pis, Appl. Surf. Sci., 2008, 254, 7165-7172.

5 B. Li, Y. Duan, D. Luebke and B. Morreale, Appl. Energy, 2013, 102, 1439-1447.

6 W. Conway, S. Bruggink, Y. Beyad, W. Luo, I. Melián-Cabrera, G. Puxty and P. Feron, Chem. Eng. Sci., 2015, 126, 446-454.

7 F. J. Tamajón, E. Álvarez, F. Cerdeira and D. Gómez-Díaz, Chem. Eng. J., 2016, 283, 1069-1080.

8 M. G. Plaza, C. Pevida, A. Arenillas, F. Rubiera and J. J. Pis, Fuel, 2007, 86, 2204-2212.

9 L. Wang, L. Ma, A. Wang, Q. Liu and T. Zhang, Chin. J. Catal., 2007, 28, 805-810.

10 M. G. Plaza, C. Pevida, B. Arias, J. Fermoso, A. Arenillas, F. Rubiera and J. J. Pis, J. Therm. Anal. Calorim., 2008, 92, 601-606.

11 G. D. Pirngruber, F. Guillou, A. Gomez and M. Clausse, Int. J. Greenhouse Gas Control, 2013, 14, 74-83.

12 R. S. Pillai and E. Titus, Materials Today: Proceedings, 2015, 2, 446-455. 
13 S. Couck, J. Lefevere, S. Mullens, L. Protasova, V. Meynen, G. Desmet, G. V. Baron and J. F. M. Denayer, Chem. Eng. J., 2017, 308, 719-726.

14 Z. Zhang, H. Wang, X. Chen, R. Xie, P. Gao, W. Wei and Y. Sun, Adsorption, 2014, 20, 883-888.

15 R. Kishor and A. K. Ghoshal, RSC Adv., 2016, 6, 898-909.

16 L. Du, Z. Lu, L. Xu and J. Zhang, RSC Adv., 2017, 7, 2126821272.

17 Z. Qiao, J. Zhou and X. Lu, Fluid Phase Equilib., 2014, 362, 342-348.

18 Z. Qiao, N. Wang, J. Jiang and J. Zhou, Chem. Commun., 2016, 52, 974-977.

19 P. Ammendola, F. Raganati and R. Chirone, Chem. Eng. J., 2017, 322, 302-313.

20 J. Wei, Z. Lin, Z. He, L. Geng and L. Liao, Water, Air, Soil Pollut., 2017, 228, 128.

21 M. Hefti, D. Marx, L. Joss and M. Mazzotti, Microporous Mesoporous Mater., 2015, 215, 215-228.

22 W.-J. Son, J.-S. Choi and W.-S. Ahn, Microporous Mesoporous Mater., 2008, 113, 31-40.

23 S. C. G. Santos, S. W. M. Machado, A. M. Garrido Pedrosa and M. J. B. Souza, J. Porous Mater., 2015, 22, 1145-1151.

24 H. Nigar, B. Garcia-Baños, F. L. Peñaranda-Foix, J. M. CataláCivera, R. Mallada and J. Santamaría, AIChE J., 2016, 62, 547555.

25 S. Loganathan and A. K. Ghoshal, Chem. Eng. J., 2017, 308, 827-839.

26 M. Niu, H. Yang, X. Zhang, Y. Wang and A. Tang, ACS Appl. Mater. Interfaces, 2016, 8, 17312-17320.

27 A. Gholidoust, J. D. Atkinson and Z. Hashisho, Energy Fuels, 2017, 31, 1756-1763.

28 Y. Zhao, Y. Shen, L. Bai, R. Hao and L. Dong, Environ. Sci. Technol., 2012, 46, 1789-1795.

29 Y. Zhao, Y. Shen, G. Ma and R. Hao, Environ. Sci. Technol., 2014, 48, 1601-1608.

30 R. Kishor and A. K. Ghoshal, Chem. Eng. J., 2015, 262, 882890.

31 X. Liu, F. Gao, J. Xu, L. Zhou, H. Liu and J. Hu, Microporous Mesoporous Mater., 2016, 222, 113-119.

32 Y. Zhao, Y. Shen and L. Bai, J. Colloid Interface Sci., 2012, 379, 94-100.

33 C. He, J. Li, X. Zhang, L. Yin, J. Chen and S. Gao, Chem. Eng. J., 2012, 180, 46-56.

34 Z. Lin, J. Wei, L. Geng, D. Mei and L. Liao, Water, Air, Soil Pollut., 2017, 228, 412.
35 P. Zeng, S. Zajac, P. C. Clapp and J. A. Rifkin, Mater. Sci. Eng., A, 1998, 252, 301-306.

36 D. Zhang, A. Duan, Z. Zhao and C. Xu, J. Catal., 2010, 274, 273-286.

37 W. Wang, J. Xiao, X. Wei, J. Ding, X. Wang and C. Song, Appl. Energy, 2014, 113, 334-341.

38 W. Wang, X. Yang, Y. Fang and J. Ding, Appl. Energy, 2009, 86, 170-174.

39 Y. Jiang, Q. Gao, H. Yu, Y. Chen and F. Deng, Microporous Mesoporous Mater., 2007, 103, 316-324.

40 V. Umamaheswari, M. Palanichamy and V. Murugesan, J. Catal., 2002, 210, 367-374.

41 M. R. Mello, D. Phanon, G. Q. Silveira, P. L. Llewellyn and C. M. Ronconi, Microporous Mesoporous Mater., 2011, 143, 174-179.

42 B. Singh and V. Polshettiwar, J. Mater. Chem. A, 2016, 4, 7071. 43 A. C. C. Chang, S. S. C. Chuang, M. Gray and Y. Soong, Energy Fuels, 2003, 17, 468-473.

44 R. Sanz, G. Calleja, A. Arencibia and E. S. Sanz-Pérez, Microporous Mesoporous Mater., 2012, 158, 309-317.

45 F. Su, C. Lu, S.-C. Kuo and W. Zeng, Energy Fuels, 2010, 24, 1441-1448.

46 J. Wei, J. Shi, H. Pan, W. Zhao, Q. Ye and Y. Shi, Microporous Mesoporous Mater., 2008, 116, 394-399.

47 C. H. Lee, D. H. Hyeon, H. Jung, W. Chung, D. H. Jo, D. K. Shin and S. H. Kim, J. Ind. Eng. Chem., 2015, 23, 251256.

48 L.-Y. Lin, J.-T. Kuo and H. Bai, J. Hazard. Mater., 2011, 192, 255-262.

49 Y. Liu, Q. Ye, M. Shen, J. Shi, J. Chen, H. Pan and Y. Shi, Environ. Sci. Technol., 2011, 45, 5710-5716.

50 D. Madden and T. Curtin, Microporous Mesoporous Mater., 2016, 228, 310-317.

51 C. Knöfel, J. Descarpentries, A. Benzaouia, V. Zeleňák, S. Mornet, P. L. Llewellyn and V. Hornebecq, Microporous Mesoporous Mater., 2007, 99, 79-85.

52 G. P. Knowles, J. V. Graham, S. W. Delaney and A. L. Chaffee, Fuel Process. Technol., 2005, 86, 1435-1448.

53 M. B. Yue, L. B. Sun, Y. Cao, Y. Wang, Z. J. Wang and J. H. Zhu, Chem.-Eur. J., 2008, 14, 3442-3451.

54 R. A. Khatri, S. S. C. Chuang, Y. Soong and M. Gray, Ind. Eng. Chem. Res., 2005, 44, 3702-3708.

55 X. Xu, C. Song, J. M. Andrésen, B. G. Miller and A. W. Scaroni, Microporous Mesoporous Mater., 2003, 62, 29-45. 